\title{
Manipulating Magneto-Optic Properties of a Chiral Polymer by Doping with Stable Organic Biradicals
}

\author{
Chang-Keun Lim, ${ }^{\dagger}$ Min Ju Cho, ${ }^{\dagger}$ Ajay Singh, Qi Li, ${ }^{\S}$ Won Jin Kim, Hong Sub Jee, Kathlyn L. \\ Fillman, ${ }^{\ddagger}$ Stephanie H. Carpenter, ${ }^{\ddagger}$ Michael L. Neidig, ${ }^{\ddagger}$ Alexander Baev, ${ }^{\dagger}$ Mark T. Swihart, ${ }^{\dagger}$ \\ $\S$ Paras N. Prasad, ${ }^{*},+$ \\ ${ }^{\dagger}$ The Institute for Lasers, Photonics and Biophotonics, State University of New York at Buffalo, Buffalo, \\ New York 14260, USA \\ ${ }^{\ddagger}$ Department of Chemistry, University of Rochester, Rochester, New York 14627, USA \\ ${ }^{\S}$ Department of Chemical and Biological Engineering, State University of New York at Buffalo, Buffalo, \\ New York 14260, USA \\ *Corresponding Author: pnprasad@buffalo.edu
}

\section{Materials and Methods.}

\section{(1a) Synthesis of chiral PF and bTbK}

Synthetic route to polyfluorene $\left(\mathrm{M}_{\mathrm{n}}=7,700\right)$ followed the general approach of Suzuki crosscoupling. ${ }^{1-3}$ We have prepared the stable organic biradical bTbK (bis-TEMPO-bisketal) using an established protocol. ${ }^{4}$ This molecule couples two TEMPO radicals via a rigid bisketal linkage to provide an exceptionally stable biradical.

\section{(1b) Computational}

Geometries of oligomers were optimized at the PM3 semi-empirical and Hartree-Fock levels. For Hartree-Fock optimization, a 6-31G* split valence basis set was used. Magneto-optic tensors were computed for all structures with Dalton electronic structure package ${ }^{5}$ and used Time Dependent Density Functional Theory (TDDFT) with the Coulomb attenuated B3LYP (CAM-B3LYP) functional ${ }^{6}$ and the $6-31 \mathrm{G}$ and $6-31+\mathrm{G}^{*}$ basis set for all atoms.

\section{Scanning electron microscopy}

Scanning electron microscopy (SEM) imaging, with a Hitachi SU-70 Field-Emission SEM operated at $5 \mathrm{kV}$, was employed to determine the film thickness of each sample. Representative edge-on secondary electron SEM images of cleaved film samples are shown in Figure S1. The viewing angle was taken into account in the SEM thickness measurements. Averages thicknesses based on multiple such measurements were used in computing the Verdet constants of the films. 

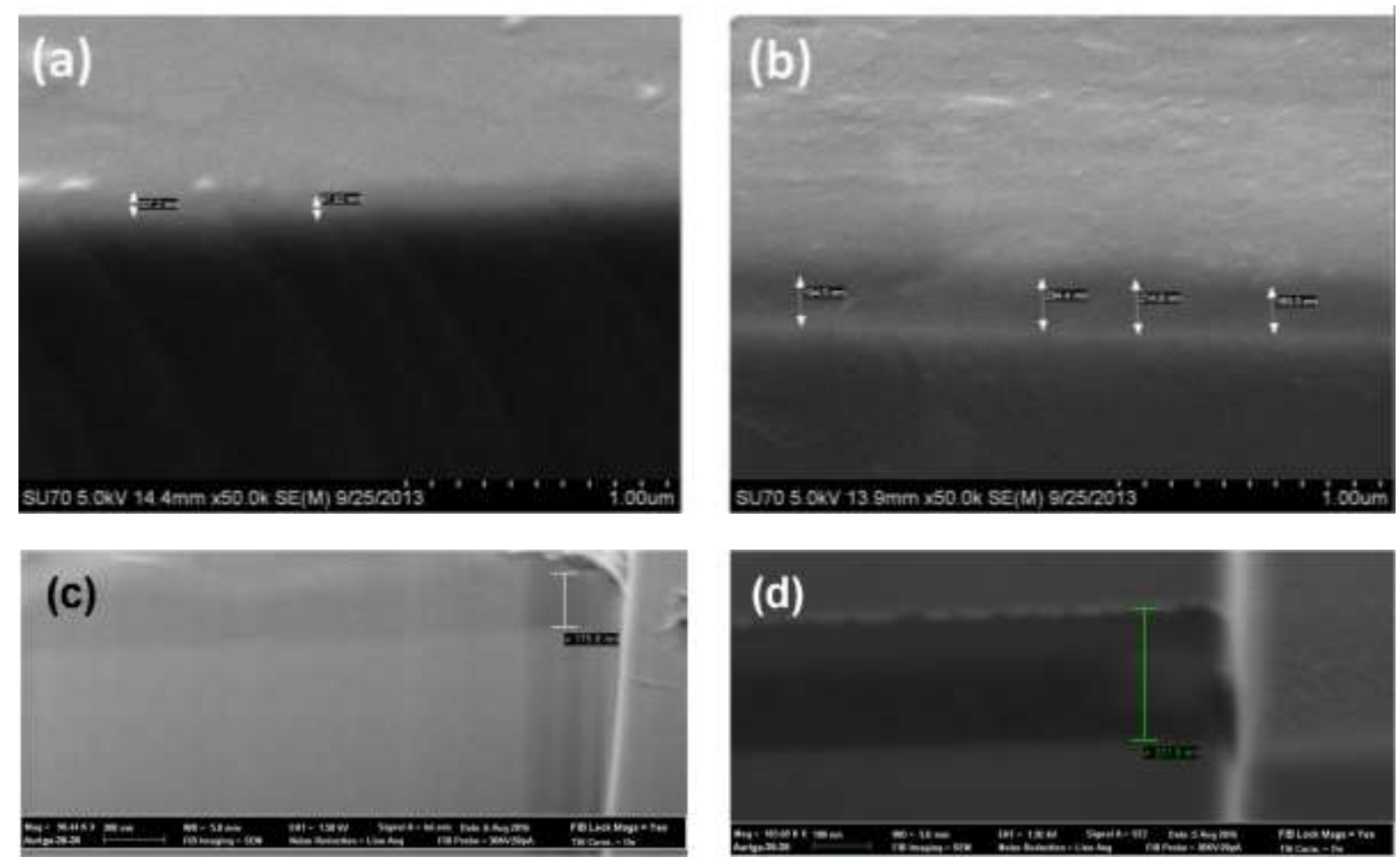

Figure S1. SEM images of (a) annealed PF film; (b) annealed PFBR film; (c) annealed PMMA film; (d) annealed PMMA+BR film. To protect the polymer films from burning by the electron beam, Au and Pt were deposited onto the top of each film.

\section{Magnetic circular dichroism spectroscopy}

MCD samples were prepared in custom copper cells a thin film sample directly deposited onto a quartz disk held within a sample cells. Low temperature UV-visible MCD spectra were collected using a Jasco J-715 spectropolarimeter and a shielded S-20 photomultiplier tube. The instruments utilizes a modified sample compartment incorporating focusing optics and an Oxford Instruments SM4000-7T superconducting magnet/cryostat. This set-up permits measurements from $1.6 \mathrm{~K}$ to $290 \mathrm{~K}$ with magnetic fields up to $7 \mathrm{~T}$. A calibrated Cernox sensor directly inserted in the copper sample holder is used to measure the temperature at the sample to $0.001 \mathrm{~K}$. Errors in the MCD intensity are estimated at $\leq 0.5$ mdeg across all wavelengths for these types of thin film samples. 


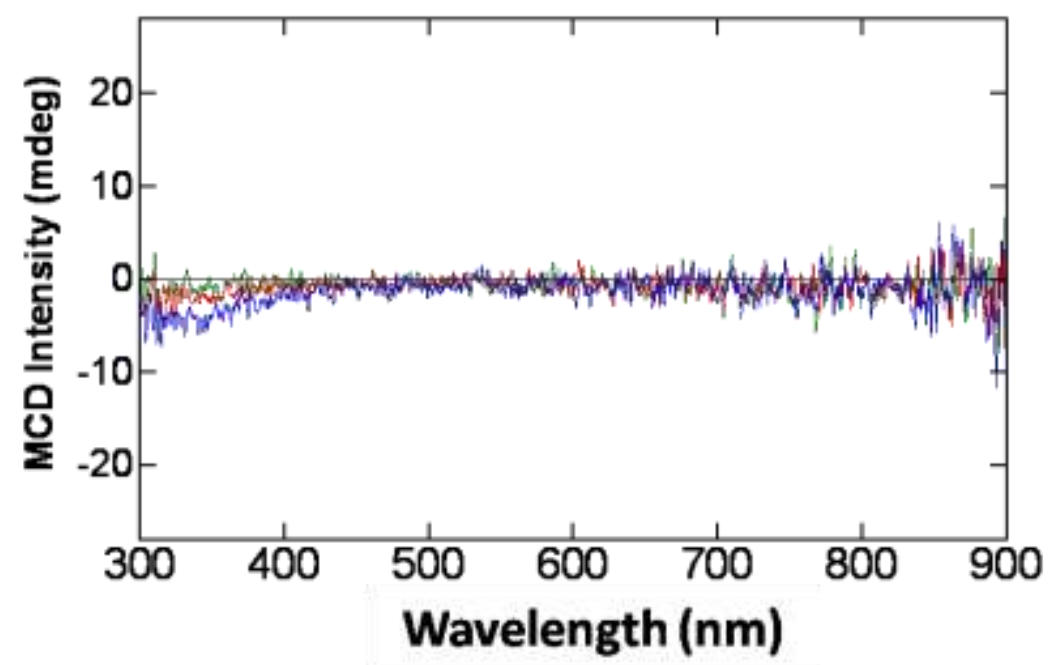

Figure S2. Results of MCD characterization of pure biradical sample at $100 \mathrm{~K}$ show the difference in $\mathrm{CD}$ from the zero field measurement to $1.5 \mathrm{~T}$ (red), $3.5 \mathrm{~T}$ (green) and $7 \mathrm{~T}$ (blue). Measurements were performed on a $10 \mathrm{mM}(3 \mathrm{mg} / 0.65 \mathrm{~mL})$ sample of biradical in 1:1THF:2MeTHF with a total pathlength of $3 \mathrm{~mm}$.

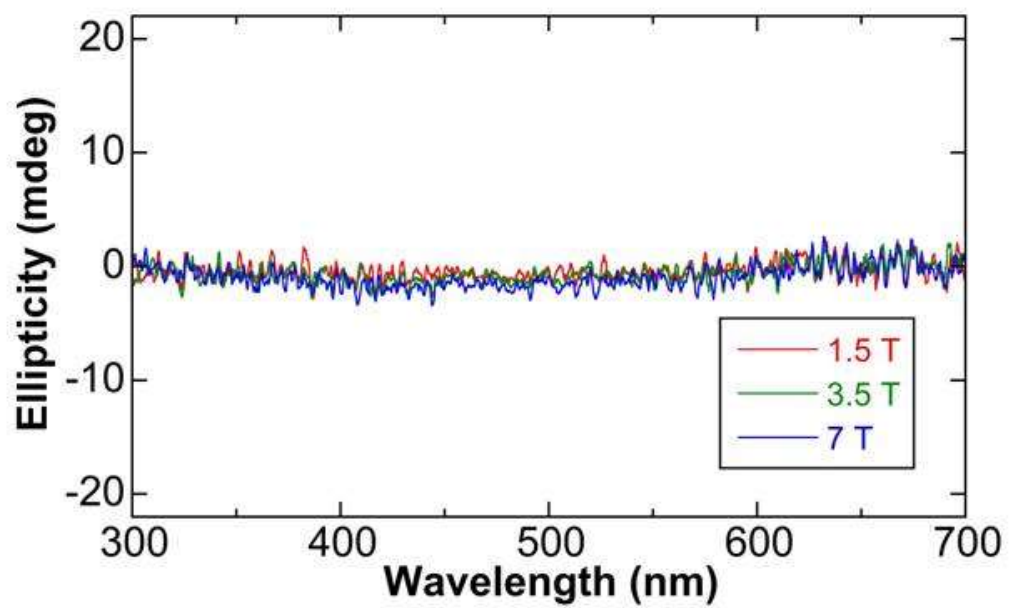

Figure S3. Results of MCD characterization of pure PF solution sample at $100 \mathrm{~K}$ show the difference in $\mathrm{CD}$ from the zero field measurement to $1.5 \mathrm{~T}$ (red), 3.5 $\mathrm{T}$ (green) and $7 \mathrm{~T}$ (blue). Measurements were performed on a $1 \mathrm{mM}(5 \mathrm{mg} / 0.6 \mathrm{~mL})$ sample of PF in 1:1THF:2-MeTHF. 

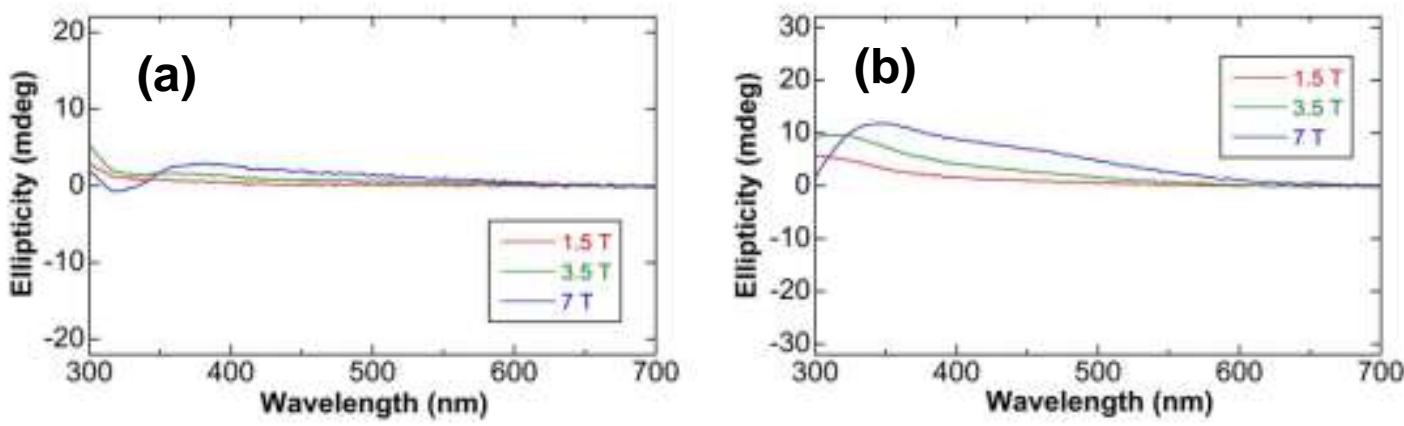

Figure S4. Results of MCD characterization of (a) pure PMMA, and (b) PMMA+BR film samples at $100 \mathrm{~K}$ show the difference in $\mathrm{CD}$ from the zero field measurement to $1.5 \mathrm{~T}$ (red), $3.5 \mathrm{~T}$ (green) and $7 \mathrm{~T}$ (blue). Measurements were performed on films cast from solutions (PMMA 15 $\mathrm{mg}+$ tolulene $0.6 \mathrm{~mL}$ for pure PMMA film or PMMA $15 \mathrm{mg}+$ biradical $9 \mathrm{mg}+$ toluene $0.65 \mathrm{~mL}$ for PMMA+BR film) and spin-coated onto quartz disks.

\section{UV-Vis spectroscopy}
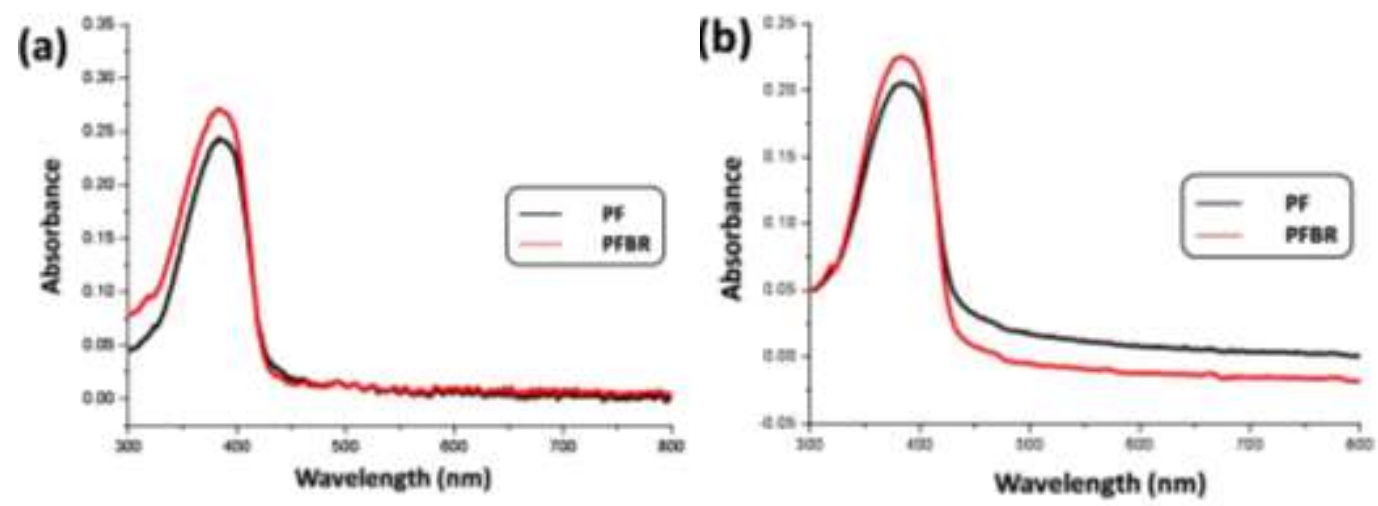

Figure S5. Absorbance spectra of (a) non-annealed, and (b) annealed PF and PFBR thin films. All measurements were done at the room temperature. Non-annealed and annealed samples were different samples prepared with the polymer from the same batch. The small "negative" absorbance of the PFBR film in (b) reflects imperfect background subtraction of the bare glass substrate. Note that the annealed PFBR film, which is slightly roughened and near $200 \mathrm{~nm}$ in thickness may have a slight "anti-reflective" effect, which makes perfect background subtraction difficult.

\section{Circular dichroism spectroscopy}



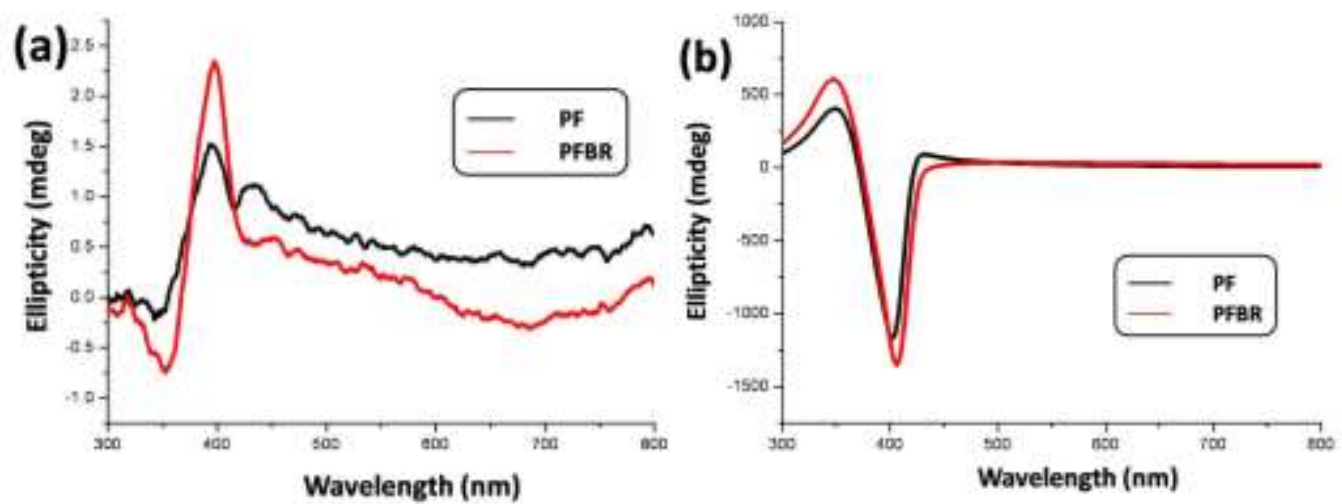

Figure S6. CD spectra of (a) non-annealed, and (b) annealed PF and PFBR thin films. All measurements were done at the room temperature. Non-annealed and annealed samples were different samples prepared with the polymer from the same batch.

\section{EPR spectroscopy}

For EPR characterization the instrument parameters used were the following: microwave power of $1 \mathrm{~mW}$, microwave frequency of $9.86 \mathrm{GHz}$, and mod. amp of $0.5 \mathrm{G}$. Spin integration using $1 \mathrm{mM}$ TEMPO standard w/ 1 spin per molecule. Both samples were prepared in toluene at $1.02 \mathrm{mM}$.

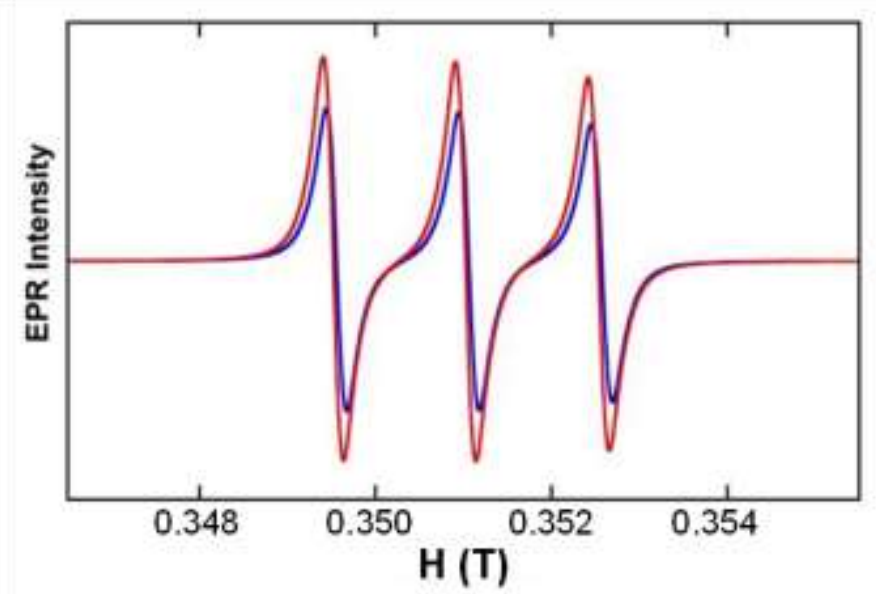

Figure S7. 298 K EPR spectra of (blue) non-annealed PFBR film, (red) annealed PFBR film. 


\section{Electronic structure calculations}

Table SI. MCD B-term tensor components of fluorene oligomers (CAM-B3LYP/6-31G).

\begin{tabular}{|l|l|r|r|}
\hline Structure & $\begin{array}{l}\text { Energy } \\
\text { (hartree) }\end{array}$ & \multicolumn{2}{|c|}{$\begin{array}{l}\text { B-term components } \\
\text { (atomic units) }\end{array}$} \\
\hline Monomer & 0.1842 & $\mathrm{YXZ}$ & 139 \\
& $(247 \mathrm{~nm})$ & $\mathrm{ZXY}$ & 292 \\
& & $\mathrm{XYZ}$ & 72 \\
& & $\mathrm{ZYX}$ & 33 \\
& & $\mathrm{XZY}$ & -561 \\
& & $\mathrm{YZX}$ & -397 \\
\hline Dimer & 0.1487 & $\mathrm{YXZ}$ & 177 \\
& $(306 \mathrm{~nm})$ & $\mathrm{ZXY}$ & 1185 \\
& & $\mathrm{XYZ}$ & 947 \\
& & $\mathrm{ZYX}$ & -100 \\
& & $\mathrm{XZY}$ & -1058 \\
& & $\mathrm{YZX}$ & 81 \\
\hline Tetramer & 0.1317 & $\mathrm{YXZ}$ & 39114 \\
& $(345 \mathrm{~nm})$ & $\mathrm{ZXY}$ & 5359 \\
& & $\mathrm{XYZ}$ & 30607 \\
& & $\mathrm{ZYX}$ & -2025 \\
& & $\mathrm{XZY}$ & -3010 \\
& & $\mathrm{YZX}$ & -3427 \\
\hline
\end{tabular}

Table SII. MCD B-term tensor components of fluorene oligomers (CAM-B3LYP/6-31+G*).

\begin{tabular}{|l|l|r|r|}
\hline Structure & $\begin{array}{l}\text { Energy } \\
\text { (hartree) }\end{array}$ & \multicolumn{2}{|c|}{$\begin{array}{l}\text { B-term components } \\
\text { (atomic units) }\end{array}$} \\
\hline Monomer & 0.1724 & YXZ & 0 \\
& $(264 \mathrm{~nm})$ & $\mathrm{ZXY}$ & -1.79 \\
& & $\mathrm{XYZ}$ & 0 \\
& & $\mathrm{ZYX}$ & 0.24 \\
& & $\mathrm{XZY}$ & -1557 \\
& & $\mathrm{YZX}$ & -2788 \\
\hline Dimer & 0.1537 & $\mathrm{YXZ}$ & 4473 \\
& $(296 \mathrm{~nm})$ & $\mathrm{ZXY}$ & 4543 \\
& & $\mathrm{XYZ}$ & -150 \\
\hline
\end{tabular}




\begin{tabular}{|r|r|r|r|}
\hline & & ZYX & -319 \\
& & XZY & 26 \\
& & YZX & 44 \\
\hline
\end{tabular}

Table SIII. Energies $\left(10^{-2} \mathrm{Hartree}\right)$ and transition dipoles (Debye) of bTbK excited triplet states (CAMB3LYP/6-31+G*).

\begin{tabular}{|l|r|r|}
\hline State no. & Energy & Dipole \\
\hline 1 & 2.29 & 0.0008 \\
\hline 2 & 2.71 & 3.25 \\
\hline 3 & 2.98 & -1.17 \\
\hline 4 & 2.99 & -1.14 \\
\hline 5 & 3.02 & -0.003 \\
\hline 6 & 3.28 & 0.08 \\
\hline 7 & 3.89 & 0.64 \\
\hline 8 & 3.91 & 0.94 \\
\hline 9 & 4.41 & 4.73 \\
\hline 10 & 4.50 & 0.79 \\
\hline 11 & 4.55 & 4.04 \\
\hline 12 & 4.78 & -0.02 \\
\hline 13 & 4.79 & 0.002 \\
\hline 14 & 4.90 & 19.50 \\
\hline 15 & 5.49 & 0.05 \\
\hline 16 & 5.59 & -1.63 \\
\hline 17 & 5.68 & -0.08 \\
\hline 18 & 5.77 & 0.005 \\
\hline 19 & 6.30 & 1.19 \\
\hline 20 & 6.38 & 0.23 \\
\hline & & \\
\hline & & \\
\hline 19 & &
\end{tabular}

\section{Figure-of-merit calculations}

For a particular application magneto-optic performance of a material should be evaluated via an appropriate figure of merit. Consider the region near $\lambda=408 \mathrm{~nm}$ where the magneto-optic response of the pure PF film is the strongest. The absorbance near this wavelength is $\sim 0.2$ (from Fig. S5), which makes transmittance $T=10^{-0.23}=0.6310$. Attenuation in $\mathrm{dB}, A=10 * \log 10(1 / \mathrm{T})=2.0 \mathrm{~dB}$ for $\sim 100 \mathrm{~nm}$ thick films. $\mathrm{A} / \mathrm{d}=2.0 \mathrm{~dB} / 10^{-7} \mathrm{~m}=2 \times 10^{7} \mathrm{~dB} / \mathrm{m}$. Verdet constant at the same wavelength is $\mathrm{V}=-$ $3.8 \times 10^{5} \mathrm{deg} / \mathrm{T} . \mathrm{m}$. The magneto-optic figure of merit, MOFOM $=\mathrm{V} /(\mathrm{A} / \mathrm{d})=-3.8 \times 10^{5} \mathrm{deg} / \mathrm{T} . \mathrm{m} /$ 
$2 \times 10^{7} \mathrm{~dB} / \mathrm{m}=-0.019 \mathrm{deg} / \mathrm{T} . \mathrm{dB}$. Absorbance at $350 \mathrm{~nm}$, where the Verdet constant is also significant (but changes sign), is only lower by a factor of 2, which implies that the pure PF film is not a good performer in the blue range. However, if we look at the red side of the spectrum, the situation changes drastically. At $450 \mathrm{~nm}$ the Verdet constant is $V=-1.6 \times 10^{5} \mathrm{deg} / \mathrm{T} . \mathrm{m}$, but the absorbance is only 0.03 . Attenuation in $\mathrm{dB}$ is then $\mathrm{A}=0.30 \mathrm{~dB}\left(\mathrm{~A} / \mathrm{d}=0.30 \mathrm{~dB} / 10^{-7} \mathrm{~m}=3.0 \times 10^{6} \mathrm{~dB} / \mathrm{m}\right)$ in which case MOFOM $=-1.6 \times 10^{5} \mathrm{deg} / \mathrm{T} . \mathrm{m} / 3.0 \times 10^{6} \mathrm{~dB} / \mathrm{m}=-0.054 \mathrm{deg} / \mathrm{T} . \mathrm{dB}-$ three times better. In general, the red shift of the Verdet constant spectrum with respect to the absorbance band provides better off-resonant MOFOM. For the PFBR film the MOFOM can reach the same order of magnitude at around 420-430 $\mathrm{nm}$ (note the positive sign of the Verdet constant). The results of MOFOM evaluation are summarized in the Fig. S8.

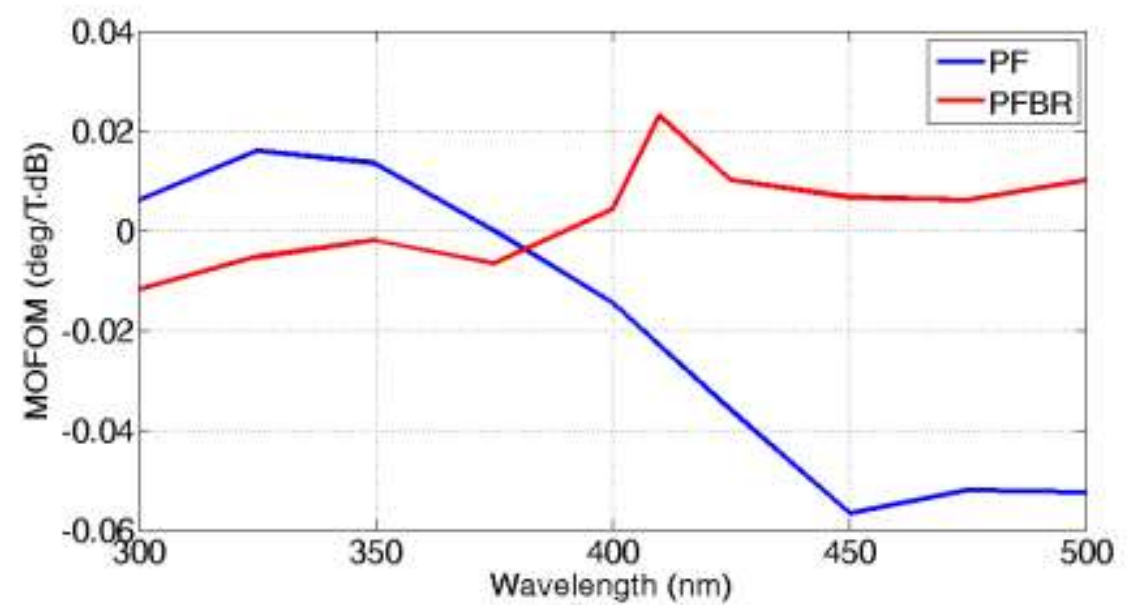

Figure S8. Magneto-optic figure-of-merit vs. wavelength

\section{REFERENCES}

(1) Miyaura, N.; Suzuki, A., J. Chem. Soc., Chem. Comm. 1979, 866-867. doi: 10.1039/C39790000866

(2) Miyaura, N.; Suzuki, A., Chem. Rev. 1995, 95, 2457-2483. doi: $10.1021 / \mathrm{cr} 00039 \mathrm{a} 007$

(3) Miyaura, N.; Yamada, K.; Suzuki, A., Tetrahedron Lett. 1979, 20, 3437-3440. doi: http://dx.doi.org/10.1016/S0040-4039(01)95429-2

(4) Matsuki, Y.; Maly, T.; Ouari, O.; Karoui, H.; Le Moigne, F.; Rizzato, E.; Lyubenova, S.; Herzfeld, J.; Prisner, T.; Tordo, P.; Griffin, R.G., Angew. Chem. Int. Ed. 2009, 48, 49965000. doi: 10.1002/anie.200805940 
(5) Aidas, K.; Angeli, C.; Bak, K. L.; Bakken, V.; Bast, R.; Boman, L.; Christiansen, O.; Cimiraglia, R.; Coriani, S.; Dahle, P.; Dalskov, E. K.; Ekström, U.; Enevoldsen, T.; Eriksen, J. J.; Ettenhuber, P.; Fernández, B.; Ferrighi, L.; Fliegl, H.; Frediani, L.; Hald, K.; Halkier, A.; Hättig, C.; Heiberg, H.; Helgaker, T.; Hennum, A. C.; Hettema, H.; Hjertenæs, E.; Høst, S.; Høyvik, I.-M.; Iozzi, M. F.; Jansík, B.; Jensen, H. J. A.; Jonsson, D.; Jørgensen, P.; Kauczor, J.; Kirpekar, S.; Kjærgaard, T.; Klopper, W.; Knecht, S.; Kobayashi, R.; Koch, H.; Kongsted, J.; Krapp, A.; Kristensen, K.; Ligabue, A.; Lutnæs, O. B.; Melo, J. I.; Mikkelsen, K. V.; Myhre, R. H.; Neiss, C.; Nielsen, C. B.; Norman, P.; Olsen, J.; Olsen, J. M. H.; Osted, A.; Packer, M. J.; Pawlowski, F.; Pedersen, T. B.; Provasi, P. F.; Reine, S.; Rinkevicius, Z.; Ruden, T. A.; Ruud, K.; Rybkin, V. V.; Sałek, P.; Samson, C. C. M.; de Merás, A. S.; Saue, T.; Sauer, S. P. A.; Schimmelpfennig, B.; Sneskov, K.; Steindal, A. H.; Sylvester-Hvid, K. O.; Taylor, P. R.; Teale, A. M.; Tellgren, E. I.; Tew, D. P.; Thorvaldsen, A. J.; Thøgersen, L.; Vahtras, O.; Watson, M. A.; Wilson, D. J. D.; Ziolkowski, M.; Ågren, H., WIREs Comput. Mol. Sci. 2014, 4, 269.

(6) Yanai, T.; Tew, D. P.; Handy, N. C., Chem. Phys. Lett. 2004, 393, 51. 